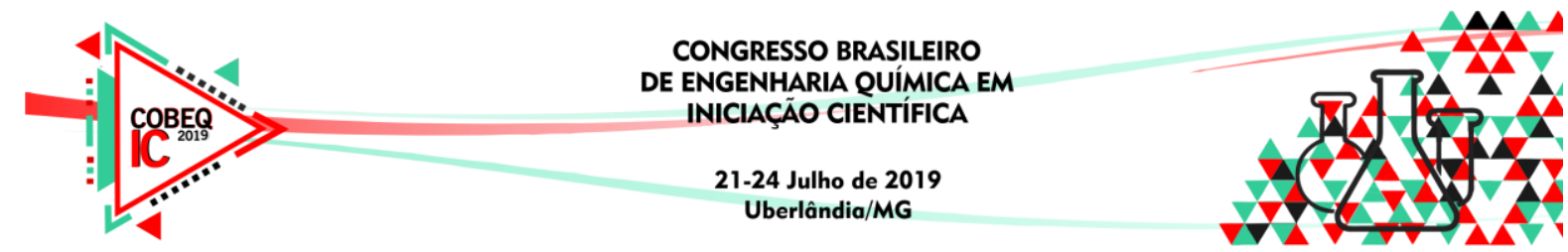

\title{
TRATAMENTO DE EFLUENTE ORIGINÁRIO DO PROCESSO DE LAVAGEM DO BIODIESEL E DA ETAPA DE BRASSAGEM DA PRODUÇÃO DE CERVEJA ARTESANAL UTILIZANDO SEMENTE DE MORINGA OLEIFERA
}

\author{
C. C. BORGO ${ }^{1}$, P. V. VALBON ${ }^{1}$, W. A. S. CRUZ 2 e P. A. B. MORAIS ${ }^{3}$ \\ ${ }^{1}$ Universidade Federal do Espírito Santo, Centro de Ciências Agrárias e Engenharias, \\ Departamento de Engenharia Rural \\ ${ }^{2}$ Laboratório de Controle de Qualidade em Saúde, COVISA/LCQS, São Paulo-SP \\ ${ }^{3}$ Universidade Federal do Espírito Santo, Centro de Ciências Exatas Naturais e da Saúde, \\ Departamento de Química e Física \\ E-mail para contato: pedro.morais@ufes.br
}

\begin{abstract}
RESUMO - A falta de saneamento básico é um dos principais problemas enfrentados pelos países subdesenvolvidos os quais apresentam um sistema precário ou são destituídos de um sistema público de abastecimento de água. Nessas áreas a população utiliza água sem nenhum tratamento prévio. Assim, constitui-se um fator de risco para a saúde das comunidades afetadas pela falta de saneamento. Além disso, os resíduos de processos industriais continuam a ser graves problemas para a contaminação de populações localizadas no entorno de indústrias produtoras de biodiesel bem como cervejarias artesanais. A coagulação é um processo comumente utilizado para a remoção de matéria orgânica em suspensão em águas, sendo utilizados vários agentes químicos como sais de alumínio e ferro. Procura-se utilizar coagulantes de origem vegetal para o tratamento de água antes dos sais químicos. Em particular, a Moringa Oleifera é classificada como uma das melhores plantas para purificação de água. Em função da capacidade coagulativa das proteínas o referido trabalho teve como intuito analisar o comportamento da semente de Moringa Oleifera, frente ao tratamento do efluente obtido através do processo de lavagem do biodiesel e da etapa de brassagem da produção de cerveja artesanal. Pode-se concluir que a semente de Moringa Oleifera tem alto poder coagulativo e clarificante nos efluentes estudados, já que se obteve uma melhora significativa nos parâmetros analisados.
\end{abstract}

\section{INTRODUÇÃO}

Uma característica de grande relevância durante o processo produtivo cervejeiro está relacionada ao consumo de grande quantidade de recursos naturais, principalmente, água a qual deve ser apropriada, com qualidade validada, para uso no preparo deste item alimentício. Observando a carga orgânica produzida na preparação industrial ou artesanal de cervejas, esta é constituída por subprodutos da fermentação e rejeitos retirados durante as etapas de limpeza, podendo ser moderada, DBO de 100 a $800 \mathrm{mg} \mathrm{L}^{-1}$ de sólidos suspensos, ou elevada, DBO de 1200 a $3000 \mathrm{mg} \mathrm{L}^{-1}$ (Santos, Ribeiro, 2005). Consequentemente deve-se observar com constante cuidado os potenciais riscos de impactos ambientais decorrentes do mau 


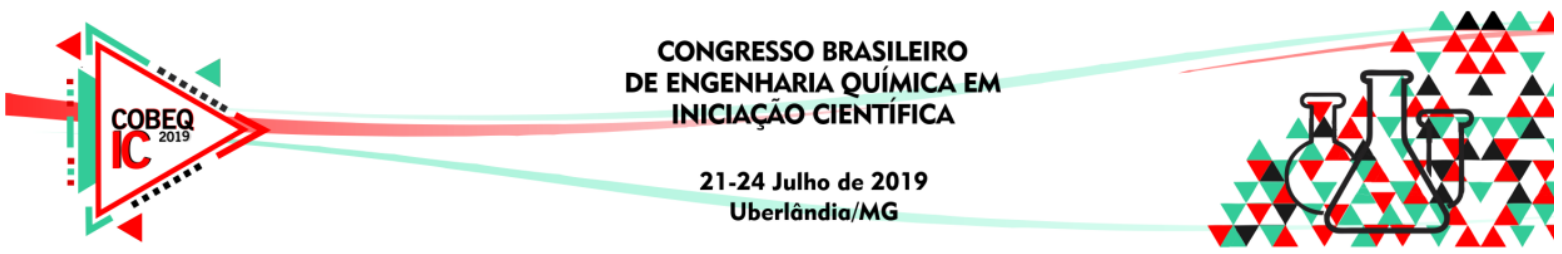

direcionamento dos efluentes produzidos uma vez que tal ação pode acarretar em vastos, e por vezes irreparáveis danos ao meio ambiente.

$\mathrm{Na}$ etapa final da reação para formação de biodiesel ocorre a lavagem para purificação, seguida por uma filtração e secagem. Durante o processo de lavagem, este é realizado com até cinco repetições dependendo da carga orgânica presente no biodiesel a qual consiste em resíduos de glicerina, sabões e ácidos graxos. Em decorrência da grande quantidade de efluente produzida, de 20 a 120 L por cada 100 L de biodiesel, a água resultante da lavagem do biodiesel é quimicamente inadequada para despejo em qualquer corpo hídrico. Do ponto de vista de preservação ambiental, há uma contínua necessidade de adoção de técnicas de tratamento, e desenvolvimento de novas técnicas mais vantajosas, para este efluente (De Meneses et al., 2012). Desta forma, o presente estudo tem como objetivo avaliar o potencial clarificante de Moringa Oleifera frente ao tratamento dos efluentes obtidos do processo de lavagem do biodiesel e da etapa de brassagem da produção de cerveja artesanal.

\section{METODOLOGIA}

O efluente, oriundo da etapa de brassagem da cerveja artesanal, foi coletado na Cervejaria Prata, localizada na região sul do Espírito Santo, na cidade de Jerônimo Monteiro. O efluente do processo de lavagem do biodiesel foi fornecido pelo Departamento de Engenharia Rural da Universidade Federal do Espírito Santo, sendo produzido em pequena escala como rejeito em trabalhos científicos. As sementes de Moringa Oleifera foram obtidas em Casa Nova, Bahia.

As sementes de Moringa Oleifera foram trituradas em um liquidificador de uso doméstico para obtenção de partículas finas e, consequente, aumento da superfície de contato entre as partículas dispersas nos rejeitos estudados e o agente clarificante. Posteriormente, foram adicionadas 0,1 gramas da semente $M$. Oleifera a $100 \mathrm{~mL}$ de ambos efluentes brutos em dois erlenmeyers de $250 \mathrm{~mL}$ para cada, os quais foram colocados em agitador magnético e mantidos sob agitação por período de 30 minutos à temperatura ambiente conforme descrito na literatura (Pozzobon, Kempka, 2015). Em seguida, os sistemas foram mantidos em repouso, sendo o erlenmeyer 1 durante 24 horas e o erlenmeyer 2, 48 horas a fim de permitir a decantação das partículas adsorvidas com o agente clarificante.

Com o intuito de avaliar a quantidade de semente a ser utilizada capaz de proporcionar maior eficácia no processo de clarificação, em um segundo ensaio, foram adicionadas as quantidades de 1,0 e 2,0 gramas de semente $M$. Oleifera a $100 \mathrm{~mL}$ de ambos efluentes brutos em 2 erlenmeyers de $250 \mathrm{~mL}$ para cada. De modo semelhante ao descrito anteriormente, ambos os sistemas foram acondicionados em agitador magnético, sob agitação por 30 minutos a temperatura ambiente, e deixados em repouso por 24 horas.

Conforme descrito na literatura a utilização de uma extração, com soluções salinas concentradas, pode promover significativamente o aumento da capacidade coagulante em virtude de uma maior obtenção do agente coagulante presente na semente de M. Oleifera (Formentini-Schimitt et al., 2014). Desta forma, a fim de avaliar um possível maior poder coagulante e, consequentemente, clarificante das amostras em questão, neste trabalho foi 


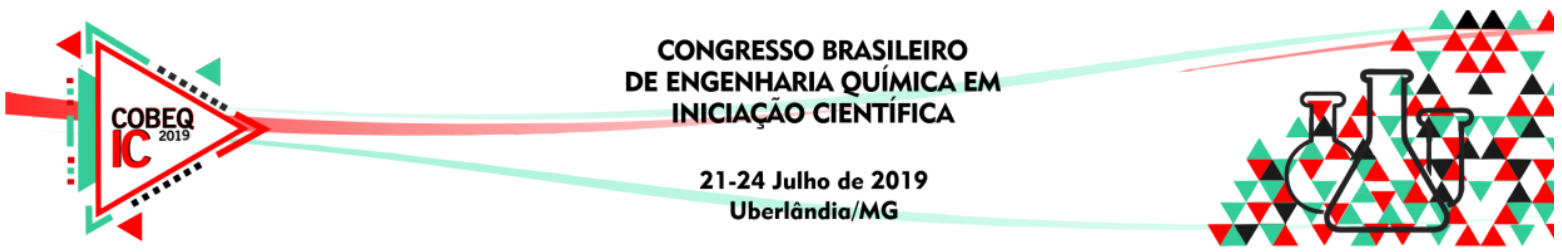

realizada também a extração dos componentes ativos das sementes de $M$. Oleifera Lam utilizando uma solução salina de $\mathrm{NaCl}$. Inicialmente, pesou-se em um erlenmeyer 14,51 gramas de $\mathrm{NaCl}$ o qual foi dissolvido em $250 \mathrm{~mL}$ de água destilada e a solução resultante colocada em agitador magnético a fim de homogeneizar a solução. Em seguida pesou-se 2,5 gramas de semente $M$. Oleifera e adicionou-se ao erlenmeyer contendo a solução salina, sendo o sistema mantido sob agitação. Com relação à agitação do sistema, a homogeneização foi realizada em duas etapas. Primeiramente, a agitação ocorreu com velocidade de $200 \mathrm{rpm}$ durante 1 minuto (mistura rápida) e, em seguida, com velocidade de $100 \mathrm{rpm}$ por 10 minutos (mistura lenta). Por fim, o sistema foi mantido em repouso por 24 horas e, em seguida, realizada uma filtração à vácuo com o auxílio de uma bomba de vácuo, funil de buchner, papel de filtro e kitassato. O precipitado foi lavado duas vezes com $10 \mathrm{~mL}$ de água deionizada. $\mathrm{O}$ precipitado obtido da extração foi adicionado a duas amostras contendo 100 $\mathrm{mL}$ de ambos efluentes brutos em erlenmeyers de $250 \mathrm{~mL}$ para cada, nas quantidades de $0,1 \mathrm{~g}$ e $1,0 \mathrm{~g}$, respectivamente, sendo mantidas em repouso por 24 horas. Da extração salina realizada com 0,1 gramas de semente $M$. Oleifera pegou-se o líquido sobrenadante e adicionou-o a $100 \mathrm{~mL}$ de ambos efluentes brutos, e foram deixados em repouso por 24 horas.

Os procedimentos supracitados foram realizados de maneira igualitária para os dois efluentes em estudo. Em seguida, com as amostras obtidas após o processo de clarificação, realizou-se as análises para avaliação de $\mathrm{pH}$ (pHmetro microprocessado Quimis), turbidez (Turbidímetro PoliControl AP 2000) e absorbância (Espectrofotômetro Kasuaki), comprimento de onda de $690 \mathrm{~nm}$.

\section{RESULTADOS E DISCUSSÃO}

\subsection{Avaliação do pH}

Na tabela 1 e 2 são apresentados os dados para a análise de $\mathrm{pH}$, onde os métodos diretos correspondem a adição da semente in natura no efluente. Com base nos dados tabelados, a máxima eficácia foi observada no método direto no tempo de 24 horas e com 2,0 gramas de semente. Dessa forma, o aumento do fator massa de semente apresentou resultado satisfatório para o parâmetro $\mathrm{pH}$. Consequentemente foi observado que nestas condições o tratamento com semente $M$. Oleifera foi capaz de reduzir razoavelmente a alcalinidade do efluente em questão, visto que a presença de ácidos graxos insaturados, principalmente o ácido oleico, na composição da semente atuam no $\mathrm{pH}$ do efluente do biodiesel na tentativa de neutralizar o mesmo.

Tabela 1 - Resultados de análise de $\mathrm{pH}$ das amostras de tratamento para o efluente de Biodiesel

\begin{tabular}{cccc}
\hline \hline Método & Tempo (horas) & $\begin{array}{c}\text { Quantidade } \\
\text { (gramas) }\end{array}$ & $\begin{array}{c}\text { Valor de pH } \\
\text { Obtido }\end{array}$ \\
\hline Direto & 24 & 0,1 & 12,921 \\
Direto & 24 & 1,0 & 12,008 \\
Direto & 24 & 2,0 & 11,449 \\
Líquido Sobrenadante & 24 & 0,1 & 11,884 \\
Extração Salina & 24 & 0,1 & 12,446 \\
Extração Salina & 24 & 1,0 & 12,414 \\
Direto & 48 & 0,1 & 12,943 \\
\hline Efluente Bruto & & & 13,259 \\
\hline \hline
\end{tabular}




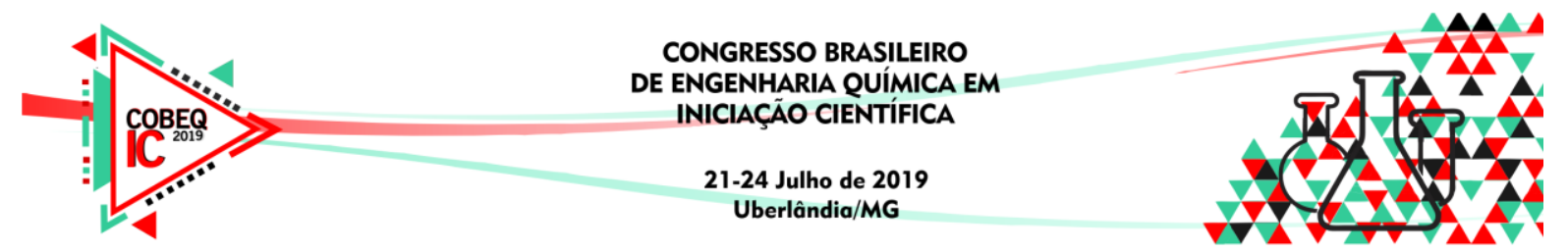

Com base nos dados da tabela 2, observa-se que os métodos utilizados para o controle de $\mathrm{pH}$ do efluente da brassagem da produção de cerveja artesanal não apresentaram resultados significativos, apresentando este efluente um $\mathrm{pH}$ ácido.

Tabela 2 - Resultados de análise de pH das amostras de tratamento para o efluente de Cerveja

\begin{tabular}{cccc}
\hline \hline Método & Tempo (horas) & $\begin{array}{c}\text { Quantidade } \\
\text { (gramas) }\end{array}$ & $\begin{array}{c}\text { Valor de pH } \\
\text { obtido }\end{array}$ \\
\hline Direto & 24 & 0,1 & 3,613 \\
Direto & 24 & 1,0 & 3,811 \\
Direto & 24 & 2,0 & 3,899 \\
Líquido Sobrenadante & 24 & 0,1 & 3,538 \\
Extração Salina & 24 & 0,1 & 3,600 \\
Extração Salina & 24 & 1,0 & 3,718 \\
Direto & 48 & 0,1 & 3,338 \\
\hline Efluente Bruto & & & 3,391 \\
\hline \hline
\end{tabular}

\subsection{Avaliação da absorbância}

Com relação à tabela 3 são apresentados os dados para a análise de absorbância do efluente do biodiesel. Observa-se que o método no qual a eficácia do tratamento mostrou-se mais relevante foi o direto no tempo de 24 horas e com 0,1 gramas de semente visto que, comparando-se esse resultado com a absorbância do efluente bruto temos uma diminuição da concentração de resíduos do efluente em 44,05\%. Dessa forma, o menor valor de absorbância obtido para o método supracitado pode ser traduzido no maior poder clarificante da semente de $M$. Oleifera, uma vez que houve uma redução no número de partículas dispersas no efluente em questão.

Tabela 3 - Resultados de análise de absorbância das amostras de tratamento para o efluente de

\begin{tabular}{cccc} 
Método & Tempo (horas) & $\begin{array}{c}\text { Quantidade } \\
\text { (gramas) }\end{array}$ & $\begin{array}{c}\text { Valor de } \\
\text { Absorbância } \\
\text { Obtido }\end{array}$ \\
\hline \hline Direto & 24 & 0,1 & 0,564 \\
Direto & 24 & 1,0 & 1,351 \\
Direto & 24 & 2,0 & 0,980 \\
Líquido Sobrenadante & 24 & 0,1 & 0,747 \\
Extração Salina & 24 & 0,1 & 1,481 \\
Extração Salina & 24 & 1,0 & 2,105 \\
Direto & 48 & 0,1 & 0,872 \\
\hline Efluente Bruto & \multicolumn{3}{c}{} \\
\hline \hline
\end{tabular}

Concomitantemente na tabela 4 , observa-se os resultados do tratamento do efluente da etapa de brassagem da cerveja artesanal para a análise de absorbância. O método o qual apresentou resultado mais expressivo foi o de extração salina no tempo de 24 horas e com 1,0 gramas de semente. Comparando este resultado ao efluente bruto temos uma diminuição da concentração de resíduos no efluente em 86,28\%. Consequentemente, a menor absorbância obtida para o tratamento do efluente da etapa de brassagem com o método com extração salina dos componentes da semente pode ser correlacionada como o maior poder clarificante 


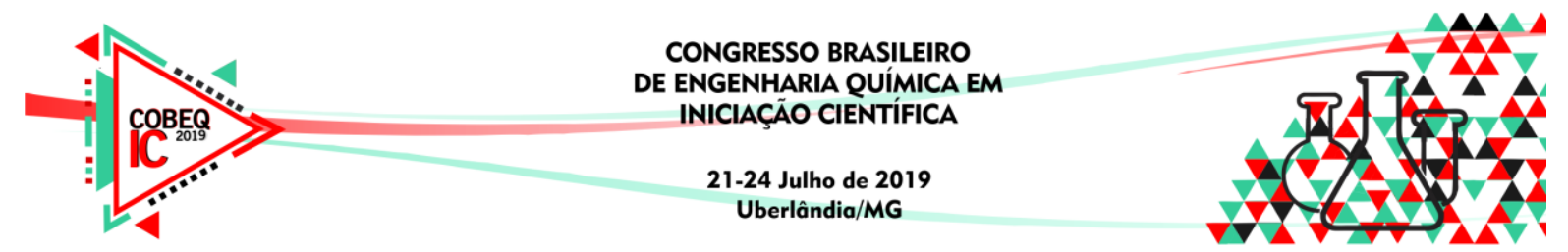

da $M$. Oleifera, visto que ocorreu uma redução no número de partículas dispersas no efluente em questão.

Tabela 4 - Resultados de análise de absorbância das amostras de tratamento para o efluente de Cerveja

\begin{tabular}{cccc}
\hline \hline Método & Tempo (horas) & $\begin{array}{c}\text { Quantidade } \\
\text { (gramas) }\end{array}$ & $\begin{array}{c}\text { Valor de } \\
\text { Absorbância } \\
\text { Obtido }\end{array}$ \\
\hline Direto & 24 & 0,1 & 0,156 \\
Direto & 24 & 1,0 & 0,101 \\
Direto & 24 & 2,0 & 0,101 \\
Líquido Sobrenadante & 24 & 0,1 & 0,284 \\
Extração Salina & 24 & 0,1 & 0,673 \\
Extração Salina & 24 & 1,0 & 0,090 \\
Direto & 48 & 0,1 & 0,400 \\
\hline Efluente Bruto & & & 0,656 \\
\hline
\end{tabular}

\subsection{Avaliação de Turbidez}

Considerando a tabela 5 são apresentados os dados para a análise de turbidez, em NTU (Unidade Nefelométrica de Turbidez), frente ao tratamento do efluente oriundo do processo de lavagem do biodiesel. Observa-se que o método no qual o resultado foi mais interessante em relação aos demais foi o direto com tempo de 24 horas e com 0,1 gramas de semente. Comparando este resultado com o efluente bruto temos uma porcentagem de clarificação $78,22 \%$. Dessa forma, o menor valor de turbidez obtido em 24 horas e com 0,1 gramas de semente está relacionado com o maior poder clarificante da semente de M. Oleifera, em virtude da redução considerável no número de partículas suspensas no efluente em questão de modo semelhante aos resultados descritos para avaliação da absorbância.

Tabela 5 - Resultados de análise de turbidez, em NTU, das amostras de tratamento para o efluente de Biodiesel

\begin{tabular}{cccc}
\hline Método & Tempo (horas) & $\begin{array}{c}\text { Quantidade } \\
\text { (gramas) }\end{array}$ & $\begin{array}{c}\text { Turbidez } \\
\text { Obtida (NTU) }\end{array}$ \\
\hline Direto & 24 & 0,1 & 72,1 \\
Direto & 24 & 1,0 & 366 \\
Direto & 24 & 2,0 & 589 \\
Líquido Sobrenadante & 24 & 0,1 & 147 \\
Extração Salina & 24 & 0,1 & 197 \\
Extracão Salina & 24 & 1,0 & 836 \\
Direto & 48 & 0,1 & 119 \\
\hline Efluente Bruto & & & 331 \\
\hline \hline
\end{tabular}

Finalmente na tabela 6 estão listados os resultados de turbidez no tratamento do efluente originário do processo de brassagem da produção de cerveja artesanal, no qual observa-se o resultado mais expressivo no método de extração salina no tempo de 24 horas e com 0,1 gramas de semente. Comparando este resultado a turbidez do efluente bruto temos uma porcentagem de clarificação de 93,99\%. Em decorrência disto, o menor valor de turbidez obtido para o método mencionado pode ser atribuído ao maior poder clarificante da semente 


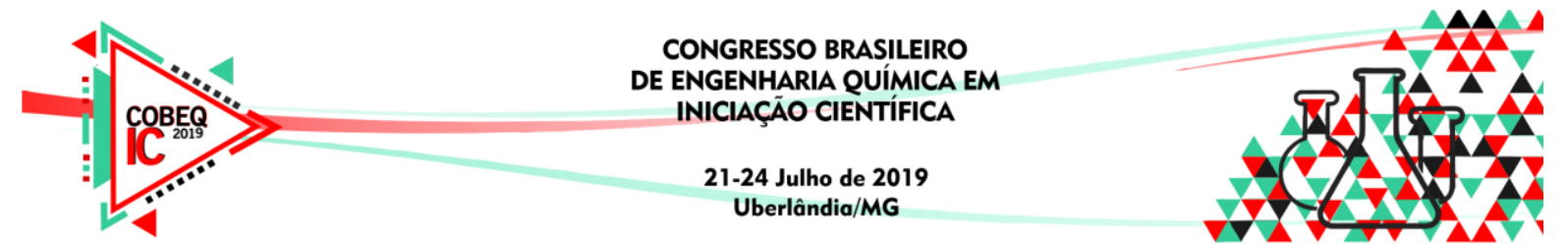

de $M$. Oleifera, visto que também ocorreu uma notória redução no número de partículas suspensas no efluente oriundo da produção cervejeira.

Tabela 6 - Resultados de análise de turbidez, em NTU, das amostras de tratamento para o efluente de Cerveja

\begin{tabular}{cccc}
\hline \hline Método & Tempo (horas) & $\begin{array}{c}\text { Quantidade } \\
\text { (gramas) }\end{array}$ & $\begin{array}{c}\text { Turbidez } \\
\text { Obtida (NTU) }\end{array}$ \\
\hline Direto & 24 & 0,1 & 31,4 \\
Direto & 24 & 1,0 & 50,9 \\
Direto & 24 & 2,0 & 48,5 \\
Líquido Sobrenadante & 24 & 0,1 & 63,8 \\
Extração Salina & 24 & 0,1 & 79,0 \\
Extração Salina & 24 & 1,0 & 43,7 \\
Direto & 48 & 0,1 & 47,2 \\
\hline Efluente Bruto & & & 523 \\
\hline \hline
\end{tabular}

\section{CONCLUSÃO}

Considerando os materiais utilizados neste estudo, rejeitos de indústria cervejeira artesanal e produção de biodiesel, os quais são inéditos em relação ao tratamento de clarificação utilizando a Moringa Oleifera, os resultados obtidos na avaliação dos parâmetros pH, absorbância e turbidez, após tratamento, confirmam que a Moringa Oleifera possui elevado poder coagulante e clarificante frente ao tratamento de efluentes agroindustriais como descrito na literatura. A aplicação de 0,1 gramas da semente de Moringa Oleifera diretamente no efluente bruto da brassagem da produção de cerveja artesanal gerou uma porcentagem de clarificação de $93,99 \%$, enquanto para o efluente da lavagem do biodiesel a porcentagem foi de $78,22 \%$ o que caracteriza um ótimo desempenho na remoção do parâmetro turbidez dos efluentes em questão.

\section{REFERENCIAS}

DE MENESES, J. M.; VASCONCELOS, R. F.; FERNANDES, T. F. F.; DE ARAÚJO, G. T. Tratamento do Efluente do Biodiesel utilizando a eletrocoagulação/flotação: investigação dos parâmetros operacionais. Quim. Nova, Vol. 35, No. 2, 235-240, 2012.

FORMENTINI-SCHMITT, D. M.; FAGUNDES-KLEN, M. R.; VEIT, M. T.; BERGAMASCO, R.; FERRANDIN, A. T. Estudo da eficiência do composto ativo de Moringa oleifera extraída com soluções Salinas na tratabilidade de águas residuárias da indústria de laticínios. ENGEVISTA, V. 16, n. 2, p.221-231, Junho 2014.

POZZOBON, L.; KEMPKA, A. P. Sementes de moringa oleifera na clarificação de efluente de indústria de ingredientes para alimentação animal: comparação com o coagulante convencional e estudo das condições operacionais. ENGEVISTA, V. 17, n. 2, p. 196206, Junho 2015.

SANTOS, M. S.; RIBEIRO, F. M. Cervejas e refrigerantes. São Paulo: CETESB, 2005.58 p. Disponível em: http://www.cete sb.sp .gov.br 